\title{
Building Technology Fluency: Fostering Agents of Change
}

\section{Dr. Wanda Eugene, University of North Carolina - Charlotte}

Dr. Wanda Eugene is a postdoctoral researcher at the University of North Carolina-Charlotte in the Computer Science Department. She completed her doctoral studies in the Human-Centered-Computing Lab in the Computer Science and Software Engineering Department at Auburn University in spring 2011. She is interested in how cultural, social, and personal surroundings affect the appropriation of computational artifacts and ideas and how they can serve as a resource for the design of new technologies. She earned a bachelor's in Electrical Engineering in 2002 from Florida State University, a master's in Industrial Engineering in 2003 from the Florida Agricultural and Mechanical University, and a master's in Interdisciplinary Studies specializing in Instructional Technology and African American Studies in 2006 from George Mason University.

\section{Dr. Shaundra Bryant Daily, Clemson University}

Dr. Shaundra Daily is an assistant professor in the School of Computing at Clemson University. She received her doctorate from the Massachusetts Institute of Technology where her doctoral work involved designing and implementing technology-infused collaborative learning environments. Prior to her doctoral studies, she received a B.S. and M.S. in Electrical Engineering from the Florida Agricultural and Mechanical University - Florida State University College of Engineering as well as a S.M. from the Massachusetts Institute of Technology. Her research interests include affective computing and STEM education, and she has received funding from the NSF and Bill and Melinda Gates Foundation to support this research. Currently, her group is designing and implementing a system to support teachers in understanding classroom engagement from a physiological perspective. Dr. Daily has authored/co-authored articles in the field of Learning Sciences as well as Computer Science Education in venues such as American Education Research Association and Conference on Human Computer Interaction.

\section{Tiffany Barnes, NC State University}

Dr. Tiffany Barnes is an associate professor of Computer Science at N.C. State University and received her Ph.D. from N.C. State in 2003. Dr. Barnes received an NSF CAREER Award for her novel work in using data to add intelligence to STEM learning environments. Dr. Barnes is co-PI on the \$9 million NSF STARS Alliance grants that engage college students in outreach, research, and service. She has received \$2 million in funds as PI from the National Science Foundation, NASA, and industry sources to research effective ways to build serious games for education, exercise, and environmental awareness; promote undergraduate research; and develop new ways to teach computing. Dr. Barnes serves on the ACM SIGCSE board, and has been on the organizing committees for several conferences including Educational Data Mining and Foundations of Digital Games, and has served as associate editor for the Journal of Educational Data Mining.

\section{Richard Burns, West Chester University}




\section{Building Technology Fluency: Fostering Agents of Change}

\section{Introduction}

Our society is rapidly transforming through the appropriation and re-appropriation of technology. This constant innovation can empower individuals and communities to be agents of change. For example, various communities in countries such as Egypt, Tunisia, and Libya are harnessing the power of mobile technology and leveraging social media to maintain a voice in the midst of political oppression. Social media have been cited as the driving force of the uprising or revolution of 2011, better known as the Arab Spring, ${ }^{1,2,3}$ in which many used blogs, Twitter, and Facebook to facilitate social activism, defuse disinformation, and effect change. Similarly, a more casual example is the use of mobile technology by fishermen, which decreased price dispersion, eliminated waste, and enabled new modes of cooperation, through the sharing of information regarding promising fishing grounds and rescue at sea. ${ }^{4}$,

Mobile, multimedia, mapping, communication, and other technologies have a tremendous potential for social empowerment; however, many of these are far from being in mainstream use. ${ }^{6}$ Opportunities must be created for a wider number of people to become creatively productive in the use of such technology. ${ }^{7}$ In this paper we present case studies of two interventions, one in Birmingham, Alabama, and another in the Republic of Haiti, where learning technology fluency was integrated with community engagement. In both locations, students designed and prototyped solutions to community problems such as adequate healthcare, accessible water, and personal finances by using computational technology.

\section{Background}

In our research, we differentiate between technical familiarity and technological fluency. Technical familiarity is proficiency in using computing for everyday tasks, and it can be demonstrated in a multitude of ways including sending and receiving electronic communications, designing electronic media, and taking advantage of digital resources. ${ }^{8}$ Technological fluency, however, involves the ability to create and express efficacious solutions through technology ${ }^{7}$, and is acquired by integrating knowledge with the ability to engage in collaboration, problemsolving, and discourse. ${ }^{9}$ Learners achieve self-perpetuating fluency when they are provided with a set of fundamental tools with which to understand technology from both a practical and social perspective. The process of building technological fluency is very similar to the classroom application of the scientific method - posing a problem, doing research, planning, developing a prototype, testing, redesigning, and sharing solutions. In this process the learner is equipped with tools for systematically addressing a problem, such that it becomes transparent to their own thinking and learning trajectories. ${ }^{10}$ 
Many today recognize that technological fluency and access to new technology allow individuals to better position themselves in life. ${ }^{9}$ As a result, such people strive to become technologically fluent in order to participate in the digital world and benefit from it. ${ }^{11}$ However from a societal view, it is vital, that individuals do not utilize these skills only for themselves but for the benefit of their communities. Social change--significant alteration over time in cultural symbols, rules of behavior, and value systems--cannot occur unless individuals employ their skills collectively to enhance their communities.

Social constructionism integrates personal and community development by focusing on initiatives that engage people in the creation of personally meaningful activities that improve their social settings. The goal, in short, is to generate an empowerment cycle wherein the activities of individuals contribute to strengthened communities that, in turn, become more conducive to the well-being of individuals. ${ }^{12}$ The interventions described below employ the social constructionist framework to address the need to develop technological fluency while actively engaging students as agents of change for their own communities. Although implemented in ways appropriate for each context, the strategy employed began with a discussion of community issues as well as solutions to existing problems. Next, workshop participants used Scratch, a programming environment developed by the MIT Media Lab Lifelong Kindergarten group, ${ }^{13}$ to express their ideas. These projects often were in the form of advertisements, stories, and games. Further details about this process are presented below.

\section{Case Study 1: Birmingham, Alabama}

The context of this summer camp was the release of XO laptops at a pilot school in Birmingham, Alabama. In the summer of 2008 we worked with twelve rising third-, fourth-, and fifth-grade students (50\% female and 92\% African American) from around the school district, as well as six teachers (83\% female and $83 \%$ African American) from the school. Only two of the students and one of the teachers had previous programming experience. During each half-day of the fourweek workshop we collaborated with students in creating health campaigns to educate their communities via advertisements and games on the XO laptops. The motivation for this workshop was threefold. (1) Biotechnology and medical research are a large part of Birmingham's economy. Known for its medical-education program and facilities, the University of Alabama at Birmingham, the largest employer in the state, is a prime resource for introducing students to healthcare issues and for providing them with opportunities to learn from healthcare professionals. (2) African American health issues are very prominent in the South and other parts of the United States. Fifty percent of all new cases of HIV are black women. Diabetes, high blood pressure, obesity, and suicide also disproportionately challenge the black community. With $73 \%$ of its population being African Americans, Birmingham is an excellent location to educate students on these issues. (3) The workshop were used as a professional development activity for 
Birmingham City Schools teachers and staff. These educators help shape the workshop's direction.

During the second week of the camp we worked with University of Alabama at Birmingham health educators to introduce students to possible topics of interest. They spent approximately one hour lecturing about substance abuse, diabetes, and emotional health. The goal of these sessions was to help students start to brainstorm ideas. On Thursday of that week we did individual and group brainstorming under the theme of "Something I would like to teach my community about healthcare." The groups that formed as a result of this activity included Diabetes Healers, Emotions Squad, Healthy Hearts, M. K. Fitness Together, Drug Stoppers, Teeth People, Got Health, and Brainiacs.

Students decided in the following week what sort of projects they would be making in Scratch. The dozen students were very enthusiastic about getting to come up with their own ideas, and the six teachers were impressed by the quality of the students' ideas and their excitement. One teacher noted that the students would get out of their parents' cars in the morning with their laptops open. Another stated, "They really did not want to stop working." By the end of the workshop students had created such projects as a newscast, three mazes, a television commercial, and a song.

The Diabetes Healers created a newscast detailing the precautions those living with diabetes should take. Each student took his or her turn describing the facts they had learned about diabetes, most of which they had conducted research themselves after a brief introduction by the University of Alabama at Birmingham health educators. Since students were not required to focus on a specific topic, the Brainiacs chose to create a futuristic story in which a man walking along a road is struck by a vehicle. Fortunately a robot is there to rescue the man, and he is taken to a local hospital where the robot shrinks itself and enters the man's brain to make the necessary repairs. After this story a game starts in which different mazes represent different parts of the brain that the robot has to enter. The creators' goal was that people would better understand the brain through interaction with the game. The team called Drug Stoppers decided that they wanted to educate the community about issues associated with drug use and abuse. They first created a discussion about the dangers of drug use as well as the possibility of death. The team ended with a song encouraging people in their neighborhoods to avoid drugs at all costs. Finally, the Emotions Squad created a maze to teach about different emotions. One of the students took pictures of himself expressing different emotions, and when a player saw a picture the game would indicate what emotion was being expressed. These projects are depicted in Figure 1 below. 


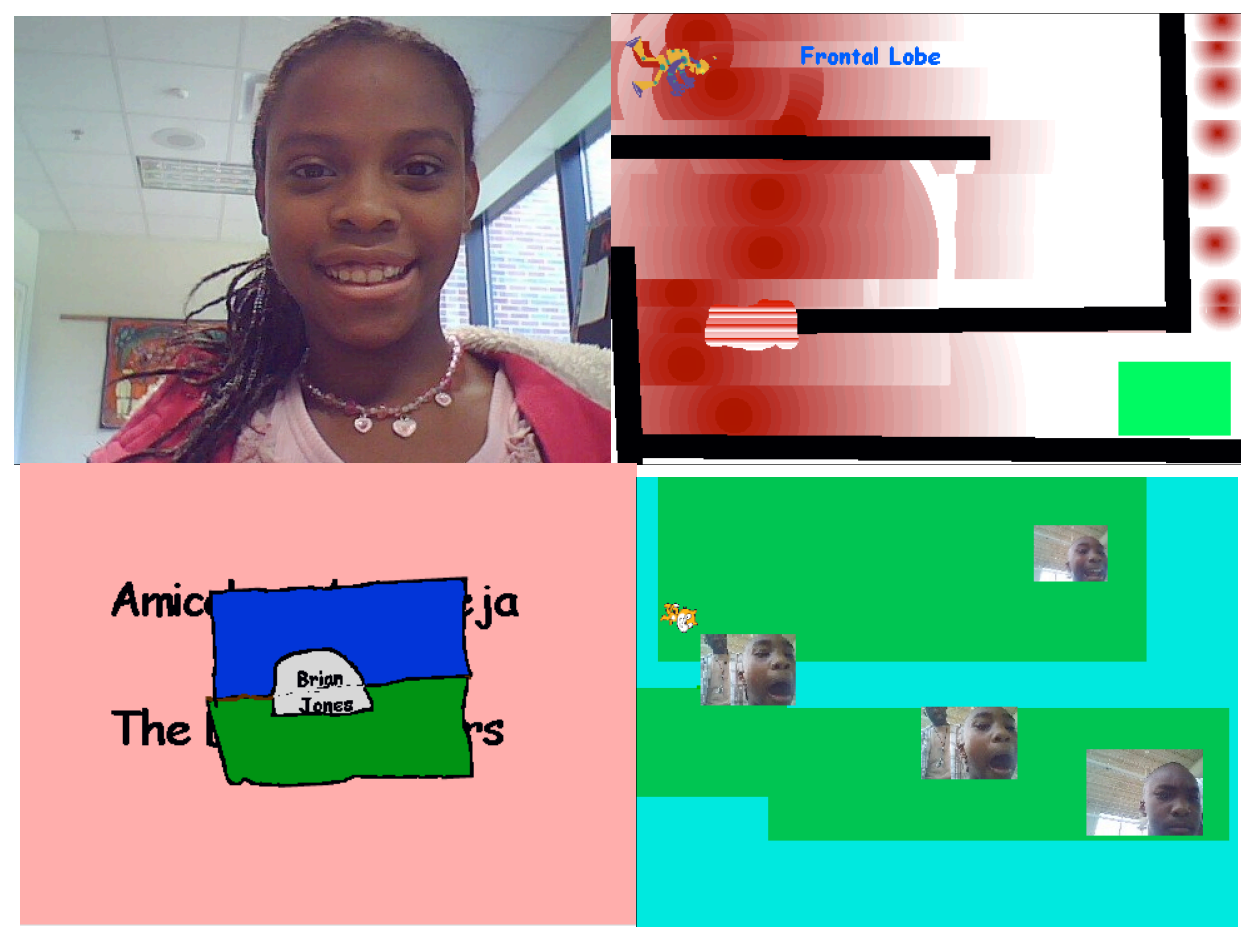

Figure 1. Clockwise from top left: Team Diabetes Healers; Team Brainiacs; Team Emotions Squad; Team Drug Stoppers.

At the end of the camp the students demonstrated their understanding of the healthcare subject matter by presenting their campaigns in a public forum. Their presentations included descriptions of their topic as well as the reasoning behind what they created. Furthermore, analysis of their Scratch projects revealed an understanding of introductory computing concepts including conditionals, function calls, sensing, and event handling. All students found the work exciting, and they were challenged to collaborate with each other. Every student expressed a desire to teach others what they had learned during the camp.

\section{Case Study 2: The Republic of Haiti}

In the spring of 2012, students and faculty from the STARS Alliance visited the Republic of Haiti and worked with twenty-four young female mentors (ages 18-32) at three different rural schools on the outskirts of the city of Cap-Haitien. At each school we spent about ten hours working with the mentors over a two-day period. Prior to our arrival these mentors taught computer classes after school on XO laptops to children in grades three through five (ages 8-15) for about six hours per week. The mentors had previously taught the children to create animations, but the learning had little connection to their schoolwork or daily lives. Although we tweaked our approach at each school, we present here the final approach utilized since it encompasses all of the practices developed from lessons learned at the first two schools. 
At the beginning of the session we began by finding a common ground with the mentors in order to build rapport. After introductions we discussed their goals, interests, and learning objectives. At all three schools language learning was discovered to be a common ground. The mentors wanted to learn English, and the STARS team members wanted to learn Kreyol. As a result, we utilized the Byke app to do a brief language-learning exercise. We next paired the mentors for a "community chat," a thoughtful round-table conversation in which they shared in detail how they perceived their community, its challenges, and possible solutions to those challenges. We then charged the groups to come up with thorough written storylines, sketches, and oral presentations of their dialogue regarding the issues in their community. Topics discussed and presented included energy, schooling, water, food, and healthcare.

Using the tutorials made available in the Scratch environment, we then devoted about two hours to taking students through the layout and structure of Scratch, using its basic features to create a program. At the end of the first session mentors were assigned homework to encourage selfexploration of Scratch and the XO laptop on their own. They also were asked to think about how the computer classes could be integrated to serve community needs. Session two began with mentors getting help on any questions or inquires they stumbled upon while doing their homework, then demonstrating their projects to the group as a whole. For the second half of session two, mentors assisted their students in doing introductory Scratch. As one of the STARS team members conducted the same introductory Scratch session with everyone in the room, the mentors floated around answering questions and helping kids troubleshoot. After the mentors and students created projects, a culminating event was held as an opportunity for participants to present their project ideas to the community.

Many of the projects were structured as scenarios to exemplify challenges faced within the community because of the lack of energy, schooling, water, food, and healthcare. Figure 2 below shows one story of life without electricity and the impact of that situation on education and quality of life. In this story the originators described completing daily chores and tasks while fumbling around in the dark by limited candlelight. As they narrated their Scratch animations in their native tongue, they also vividly situated their stories in images and dialogue. For example, one group talked about food disparities and then created images that included bags of rice and coconut trees, both representing staple food items in the island nation. 



Figure 2. Clockwise from top left: "community chat"; mentors assisting students in sketching out their projects; mentors converting handwritten stories into online animations; students presenting their work to peers and community members.

\section{Discussion and Conclusion}

In this paper we have discussed the potential and importance of technological fluency as a vehicle for community empowerment. Through technology individuals can prototype and communicate solutions to complex problems in their communities. We presented two cases involving the application of social constructionism in which students embraced the idea of developing technological fluency for the betterment of their community in a way that could ultimately impact their own lives. In our cases students utilized the XO laptop and explored basic computational concepts for the creation of their ideas. Based on our interactions with Scratch, we found that the majority of the "blocks" used by the students were either conditionals or motion, suggesting that sequencing and case-based sequencing were vital for conveying the students' final products. The technological fluency of basic computation was a facilitator.

In both case contexts participant excitement was contagious: teachers observed a change in their students' demeanor as well as a change in the classroom's environment. An important motivating factor for the students was their freedom to construct a movie, program, or advertisement, etc. on a community-based topic of their choosing. They embraced collaboration with their peers. Equally important, they embraced the presentation of their final product to others for the enhancement of their communities. 
Through these experiences we have learned the importance of the following:

- Creating a safe space for a discussion of community challenges so that participants feel comfortable discussing personal experiences.

- Allowing ideas to originate from participants organically rather than being handed down.

- Providing adequate support to scaffold participants' use of technology in order to express ideas. The amount of support varies based on the previous experience of the participants and should be assessed prior to the workshop.

- Helping participants become experts of their own situation in order to facilitate ownership and a desire to persist.

In summary, enabling students to imagine approaches to improving their communities will plant the seeds for them to view themselves as "agents of social change". By incorporating the development of technological fluency into the approach, instructors can promote the skills necessary for capitalizing on the potential of new technologies. Based on our observations and analysis of the actual programs, we will present in future work the quantitative and qualitative results of surveys that we administered.

\section{References}

1 Cottle, S. (2011). Media and the Arab Uprisings of 2011: Research Notes. Journalism 12(5):647-659. doi:10.1177/1464884911410017

2 Attia, A. M., Aziz, N., Friedman, B., and Elhusseiny, M. F. (2011). Commentary: The Impact of Social Networking Tools on Political Change in Egypt's "Revolution 2.0." Electronic Commerce Research and Applications.

3 Ghannam, J. (2011, March 12). Freedom Beyond 140 Characters. The Herald-Sun.

4 Jensen, R. (2007). The Digital Provide: Information (Technology), Market Performance, and Welfare in the South Indian Fisheries Sector. Quarterly Journal of Economics 122(3):879-924.

5 Sreekumar, T. T. (2011). Mobile Phones and the Cultural Ecology of Fishing in Kerala. Information Society 27(3):172-180.

6 Burd, L. (2007). Technological Initiatives for Social Empowerment: Design Experiments in TechnologySupported Youth Participation and Local Civic Engagement. Doctoral dissertation, Massachusetts Institute of Technology. 
7 Resnick, M., and Rusk, N. (1998). The Computer Clubhouse: Technological Fluency in the Inner City. In High Technology and Low-Income Communities: Prospects for the Positive Use of Advanced Information Technology edited by D. Schon, B. Sanyal, and W. Mitchell. Cambridge: MIT Press, 1998: 266-286.

8 Christensen, E., Anakwe, U., and Kessler, E. (2001). Receptivity to Distance Learning: The Effect of Technology, Reputation, Constraints, and Learning Preferences. Journal of Research on Computing in Education 33(3):263-276.

9 Barron, B., Martin, C., and Roberts, E. (2002). A Design Experiment to Build Technological Fluency and Bridge Divides. Proceedings of the Fifth International Conference of the Learning Sciences. Seattle, Washington, October 2002.

10 Bers, M. (2010). The Tangible K Robotics Program: Applied Computational Thinking for Young Children. Early Childhood Research \& Practice 12(2). Retrieved from http://ecrp.uiuc.edu/v12n2/bers.html.

11 Cavallo, D. (2004). Models of Growth-Towards Fundamental Change in Learning Environments. BT Technology Journal 22(4):96-112. doi:10.1023/B:BTTJ.0000047588.81509.4c

12 Shaw, A. (1996). Social Constructionism and the Inner City. In Y. B. Kafai and M. Resnick (eds.), Constructionism in Practice: Designing, Thinking, and Learning in a Digital World. Routledge.

13 Resnick, M., Maloney, J., Monroy-Hernández, A., Rusk, N., Eastmond, E., Brennan, K., and Kafai, Y. (2009). Scratch: Programming for All. Communications of the ACM 52(11):60-67.

doi:10.1145/1592761.1592779 